\title{
PEMERTAHANAN LEKSIKON DAN MAKNA KULTURAL MOTIF BATIK KEBUMEN SEBAGAI UPAYA PRESERVASI WARISAN BUDAYA BANGSA
}

\author{
Yuli Kristianingsih \\ Universitas Sebelas Maret, Surakarta, Indonesia \\ Email: yulika.kris17@gmail.com \\ Nur Faidah \\ Universitas Sebelas Maret, Surakarta, Indonesia \\ Email: faidahnoer@gmail.com \\ Yulia Cahyani \\ Universitas Sebelas Maret, Surakarta, Indonesia \\ Email: liacahya8799@gmail.com
}

\section{Article history:}

Submitted Sept 29, 2020

Revised Oct 12, 2020

Accepted Jan 11, 2021

Published June 13, 2021

\begin{abstract}
Kebumen batik is not as widely known as batik from Jogja, Surakarta, and Pekalongan. This is due to several factors, such as marketing, age, and production imbalances. One way to preserve Kebumen batik is by describe and maintain lexicons and cultural meanings contained in batik in Gemeksekti Village, Kebumen Regency. Gemeksekti Village is one of the batik centers in Kebumen which has been named the village of Kebumen batik. The method used in writing this article is a descriptive qualitative method with literature review techniques. Based on the data obtained, there were 143 batik lexicons. The lexicons were 64 batik lexicons based on tools and materials, 31 batik lexicons based on the batik process, 48 batik lexicons based on motives. Batik motifs in Kebumen not only have philosophical value, but their depiction is also based on artistic value. Cultural values from several Kebumen batik motifs can be found in gringsing, sirikit, limaran, and ukel motifs. The lexicon findings can be made in to dictionaries and books containing batik motifs, explanation of motifs, pictures, and the history of Kebumen batik and other media. Both of them may be used as a means for introduction to the wider community and the preservation of Kebumen batik.
\end{abstract}

Keywords: batik Kebumen; lexicon; batik motif; cultural meaning; preservation

\section{ABSTRAK}

Batik Kebumen belum dikenal luas seperti halnya batik dari Jogjakarta, Surakarta, dan Pekalongan. Hal ini disebabkan oleh beberapa faktor, seperti pemasaran, usia, dan ketidakseimbangan produksi. Salah satu cara 
Yuli Kristianingsih, Nur Faidah, Yulia Cahyani- Pemertahanan Leksikon dan Makna Kultural Motif Batik Kebumen sebagai Upaya Preservasi Warisan Budaya Bangsa

melestarikan batik Kebumen yaitu dengan mendeskripsikan dan mempertahankan leksikon dan makna kultural yang terdapat dalam perbatikan di Desa Gemeksekti, Kabupaten Kebumen. Desa Gemeksekti merupakan salah satu sentra batik di Kebumen yang telah dinobatkan sebagai kampung batik Kebumen. Metode yang digunakan dalam penulisan artikel ini adalah metode deskriptif kualitatif dengan teknik kajian pustaka. Berdasarkan data yang diperoleh, ditemukan sebanyak 143 leksikon. Leksikon tersebut yaitu 64 leksikon perbatikan berdasarkan alat dan bahan, 31 leksikon perbatikan berdasarkan proses membatik, 48 leksikon perbatikan berdasarkan motif. Motif batik di Kebumen tidak hanya memiliki nilai filosofi, tetapi penggambarannya juga berdasarkan nilai artistik. Makna kultural dari beberapa motif batik Kebumen dapat ditemukan pada motif batik gringsing, sirikit, limaran, dan ukel. Hasil temuan leksikon dapat dibuat menjadi kamus dan buku yang berisi motif batik, penjelasan motif, gambar, maupun sejarah batik Kebumen dan media lainnya. Kedua media tersebut dapat dijadikan sebagai sarana untuk pengenalan ke masyarakat luas serta pelestarian batik Kebumen.

Kata kunci: batik kebumen; leksikon; motif batik; makna kultural; preservasi

\section{PENDAHULUAN}

Batik merupakan warisan kebudayaan Indonesia yang telah ditetapkan oleh United Nations Educational, Scientific, and Cultural Organisation (UNESCO) sejak 2 Oktober 2009 (Prasetyo, 2010). Oleh karena itu, setiap tanggal 2 Oktober diperingati sebagai Hari Batik. Semenjak itu, nilai ekspor dari industri batik sepanjang semester I Tahun 2019 mencapai 17,99 juta dolar AS dengan tujuan utama pengapalan antara lain ke Jepang, Amerika Serikat, dan Eropa (Gareta, 2019). Batik di Indonesia memiliki corak beragam yang di dalamnya mengandung makna kultural serta makna filosofis yang menggambarkan suatu keadaan masyarakat (Nanang, 2018). Hal tersebut juga dapat dilihat dari motif dan warna batik. Kota penghasil batik yang terkenal yaitu Jogja, Solo, dan Pekalongan. Batik-batik di daerah tersebut dinilai memiliki nilai filosofis yang tinggi. Daerah lain yang memproduksi batik, yaitu Kebumen.

Kebumen memiliki sentra batik yaitu di Desa Gemeksekti, Dusun Tanuraksan, Dusun Watubarut, Desa Kambangsari, Kecamatan Alian, dan Desa Jemur Pejagoan. Sentra batik di Kebumen tergabung dalam persatuan batik yang bernama Batik Lawet Sakti (Khoerunnisa, 2012). Konon batik tulis 
Yuli Kristianingsih, Nur Faidah, Yulia Cahyani- Pemertahanan Leksikon dan Makna Kultural Motif Batik Kebumen sebagai Upaya Preservasi Warisan Budaya Bangsa

Kebumen sudah ada sejak abad 19 (Fitinline, 2013). Batik masuk ke Kebumen dibawa oleh seorang pendakwah untuk mengajarkan ajaran Islam. Eksistensi batik Kebumen sebenarnya cukup meyakinkan. Paling tidak berdasarkan beberapa pengakuan pengrajin, seperti ketua kelompok batik Kenanga, bahwa kelompok mereka pernah menjadi juara I lomba motif Dekranasda 2005 dan juara 11 lomba motif batik Disperindagkop Kebumen 2008. Pemasaran batik tersebut sudah masuk ke hotel-hotel di Jakarta, Balai Graha Santika dan melaiui DWP Jakarta (Nurhidayat, 2010).

Akan tetapi, industri perbatikan di Kebumen dapat dikatakan kurang dikenal. Hal ini disebabkan kurangnya sosialisasi dari pemerintahan perihal batik Kebumen. Selain itu, berdasarkan data Disperindagkop Kabupaten Kebumen pada tahun 2009 dan data dari Kepala Dusun Tanuraksan 2011, terjadi penurunan jumlah perajin batik (Khoerunnisa, 2012). Hal ini disebabkan oleh beberapa faktor, diantaranya faktor usia dan sulit mencari generasi penerus batik. Selain itu, ketidakseimbangan antara biaya produksi batik (dilihat dari waktu, tenaga dan biaya) dengan hasil yang diperoleh menyebabkan perajin beralih profesi ke pekerjaan lain. Oleh karena itu, perlu dilakukan upaya preservasi atau pelestarian terhadap batik di Kebumen.

Salah satu cara melestarikan batik, yaitu dengan mendeskripsikan leksikon dan makna kultural yang terdapat dalam perbatikan di Desa Gemeksekti, Kabupaten Kebumen. Leksikon adalah komponen bahasa yang memuat semua informasi tentang makna dan pemakaian kata dalam suatu Bahasa (Kridalaksana, 1994). Adapun makna kultural adalah unsur-unsur budaya yang diungkapkan menggunakan arti secara khas dan juga aspek kebudayaan yang khas untuk keperluan budaya (Subroto, 2011). Kedua hal tersebut termasuk dalam kajian etnolinguistik. Etnolinguistik berasal dari dua kata yaitu etnografi dan linguistik. Menurut Spradley (2007), etnografi adalah suatu pekerjaan atau kegiatan untuk mendeskripsikan suatu kebudayaan. Sedangkan linguistik adalah suatu bidang ilmu tentang bahasa yang menyelidiki bahasa secara ilmiah (Kridalaksana, 2008). 
Yuli Kristianingsih, Nur Faidah, Yulia Cahyani- Pemertahanan Leksikon dan Makna Kultural Motif Batik Kebumen sebagai Upaya Preservasi Warisan Budaya Bangsa

Penelitian batik dengan kajian etnolinguistik pernah dilakukan oleh Purnamasari (2016), Fatehah (2010), dan Purwaningsih dkk. (2018). Purnamasari (2016) dalam jurnalnya yang berjudul Sejarah Perkembangan, Makna dan Nilai Filosofis Batik Srikit Khas Kabupaten Kebumen membahas tentang sejarah, makna simbolik, dan nilai filosofis yang terdapat di dalam batik srikit khas Kebumen. Selain itu, Fatehah (2010) dalam jurnalnya yang berjudul Leksikon Perbatikan Pekalongan (Kajian Etnolinguistik) membahas tentang leksikon perbatikan di Pekalongan. Penelitian Purwaningsih dkk. (2018) tentang Redefining Banyumas Local Values: Symbolisms In Batik Motifs yang merupakan kajian semiotika. Berdasarkan hal tersebut, maka penelitian ini akan membahas tentang leksikon-leksikon perbatikan dan makna kultural motif batik dan warna batik di Desa Gemeksekti Kabupaten Kebumen.

Objek dalam penelitian ini adalah batik di Desa Gemeksekti, Kabupaten Kebumen. Desa Gemeksekti terletak pada 109³8'34"BT-109³9'43"BT dan $7^{\circ}$ 38'44"LS-70 39'32"LS (Suharto, 2020). Berdasarkan letak administratif, Desa Gemeksekti termasuk wilayah administratif Kecamatan Kebumen, Kabupaten Kebumen, Provinsi Jawa Tengah. Desa Gemeksekti memiliki luas wilayah 162,4 ha dengan ketinggian tempat 21 meter diatas permukaan air laut (dpl). Desa Gemeksekti terbagi menjadi empat dusun, yaitu Dusun Tanuraksan, Dusun Watubarut, Dusun Tangkil, dan Dusun Sumelang. Dipillihnya Desa Gemeksekti sebagai lokasi penelitian, karena daerah ini adalah salah satu sentra batik yang telah dinobatkan sebagai kampung batik Kebumen. Selain itu, berdasarkan sejarah, dusun Tanuraksan dan dusun Watubarat merupakan tempat batik pertama kali dikenalkan di Kebumen oleh para pendakwah Islam sekitar abad ke-20 atau lebih tepatnya abad ke-19.

\section{TEORI DAN METODOLOGI}

Penelitian mengenai leksikon batik dan makna kultural sudah pernah dilakukan oleh peneliti terdahulu. Nur Fatehah (2010) dalam jurnalnya yang berjudul Leksikon Perbatikan Pekalongan (Kajian Etnolinguistik) membahas tentang 
leksikon batik yang berada di Pekalongan. Penelitian tersebut (1) mengklarifikasikan leksikon perbatikan yang berada di Pekalongan, (2) mendeskripsikan leksikon-leksikon batik yang berada di Pekalongan, dan (3) refleksi dari identitas kebudayaan berdasarkan leksikon pada perbatikan. Penelitian tersebut menggunakan pendekatan etnolinguistik untuk menganalisis hubungan budaya dengan bahasa. Leksikon perbatikan yang berada di Pekalongan merupakan kekayaan tersendiri bagi masyarakatnya. Hal ini dikarenakan leksikonnya yang banyak dan sangat bervariasi.

Leksikon perbatikan di Pekalongan dapat diklasifikasikan berdasarkan perlengkapan atau peralatan yang digunakan dalam membatik, bahan membatik, kain batik berdasarkan tempat penghasil batik, proses pembuatan batik Pekalongan dan berdasarkan keberagaman dari motif batik. Leksikon perbatikan di Pekalongan berdasarkan struktur kata dapat diklasifikasikan menjadi kata yang berstruktur monomorfemik dan kata yang berstruktur polimorfemik. Tetapi, dalam juga terdapat yang berstruktur frasa.

Leksikon perbatikan berfungsi sebagai (1) khasanah kekayaan bahasa, identitas sosial pembagian kerja berdasarkan gender; (2) identitas sosial berdasarkan strata ekonomi; (3) identitas keagamaan; dan (5) sebagai bingkai budaya pesisir. Leksikon perbatikan di Pekalongan mangandung kebudayaan yang terwujud dalam ungkapan-ungkapan yang digunakan dalam keseharian oleh masyarakat di Pekalongan.

Penelitian tentang makna kultural batik Kebumen juga pernah dilakukan oleh Diah Ayu Purnamasari (2015) yang berjudul Sejarah Perkembangan, Makna dan Nilai Filosofis Batik Srikit Khas Kabupaten Kebumen. Penelitian tersebut membahas tentang (1) sejarah perkembangan, (2) makna simbolik, (3) nilai filosofis yang terdapat di dalam batik srikit khas Kebumen.

Berdasarkan penelitian tersebut diperoleh hasil (1) bahwa sejarah perkembangan motif batik srikit sangat berhubungan dengan masyarakat di Kebumen dalam mengusir penjajah Belanda pada saat penjajahan, (2) makna simbolik dalam batik srikit yaitu makna simbolik rante yang memili makna 
Yuli Kristianingsih, Nur Faidah, Yulia Cahyani- Pemertahanan Leksikon dan Makna Kultural Motif Batik Kebumen sebagai Upaya Preservasi Warisan Budaya Bangsa

suatu ikatan yang tidak terputus, kemakmuran disimbolkan dengan beras wutah, kesehatan disimbolkan dengan gringsing, keharuman disimbolkan dengan kembang cengkeh dan kopi pecah, tumbuh dengan kedinamisan disimbolkan dengan lung pakis, warna hijau memiliki makna ke Tuhanan, warna biru memiliki makna ketinggian, warna sogan melambangkan warna tanah, dan (3) batik srikit mengandung nilai filosofis yaitu suatu keindahan yang mengikat, perbedaan yang indah dari suatu persatuan. Penelitian yang telah dilakukan oleh Diah Ayu Purnamasari (2015) hanya membahas tentang batik srikit saja dan tidak membahas tentang leksikon perbatikan. Selain itu, dalam penelitian Nur Fatehah (2010) tentang leksikon perbatikan di Pekalongan hanya mengangkat tentang batik Pekalongan. Berdasarkan hal tersebut, maka penelitian ini akan membahas tentang leksikon perbatikan dan makna kultural warna dan motif batik di Desa Gemeksekti Kabupaten Kebumen.

Penulisan narrative review ini menggunakan metode deskriptif kualitatif. Penelitian deskriptif menggunakan kata-kata, gambar, dan bukan angka-angka untuk mendeskripsipsikan data (Muhammad, 2011). Dalam penelitian ini, tahap yang dilakukan yaitu dengan mengumpulkan, mereduksi, mengindentifikasi dan menganalisis data yang diperoleh terkait leksikon dan makna kultural motif batik di Desa Gemeksekti, Kecamatan Kebumen, Kabupaten Kebumen.

Data yang digunakan dalam penelitian ini merupakan data sekunder yang diperoleh dari kajian pustaka di berbagai sumber online, yaitu google search, portal Garuda, SINTA (science and technology index), Rama Repository, ISJD (Indonesian Scientific Journal Database), Google Scholar, Academia.edu, ResearchGate, Google Books, dan melalui software reference manager yaitu Mendeley. Kajian pustaka dilakukan dengan mengumpulkan data dari berbagai sumber tersebut menggunakan kata kunci yang berkaitan dengan batik Kebumen.

Analisis data dilakukan secara deskriptif. Setelah data terkumpul, dilakukan reduksi dengan memilah dan memusatkan data . Reduksi data bertujuan untuk mempermudah proses identifikasi dan analisis data leksikon 
Yuli Kristianingsih, Nur Faidah, Yulia Cahyani- Pemertahanan Leksikon dan Makna Kultural Motif Batik Kebumen sebagai Upaya Preservasi Warisan Budaya Bangsa

yang ada di perbatikan Kebumen. Data yang telah direduksi, kemudian diidentifikasi dan dianalisis sehingga ditemukan leksikon dan makna kultural motif batik Kebumen. Hasil leksikon tersebut kemudian diklasifikasikan berdasarkan alat dan bahan, proses, dan motif batik di Kebumen. Motif batik Kebumen diklasifikasikan berdasarkan penggambaran motifnya, yaitu makna kultural atau nilai artistik. Setelah pengklasifikasian data, langkah selanjutnya yaitu penarikan kesimpulan menggunakan teknik penarikan kesimpulan induktif.

\section{HASIL DAN PEMBAHASAN}

\section{a. Leksikon Perbatikan}

Setiap daerah memiliki bahasa yang berbeda. Oleh karena itu, antara satu bahasa dengan bahasa lainnya sudah pasti memiliki perbedaan dari leksikonnya Perbedaan leksikon dapat disebabkan oleh berbagai macam hal yang ada dalam budaya masyarakat pengguna suatu leksikon (Gani and Arsyad, 2019). Hal ini terjadi dalam keseharian, termasuk dalam leksikon di perbatikan Kebumen. Masyarakat perbatikan dengan masyarakat umum memiliki konsep yang berbeda untuk menyebut suatu konsep yang sama, misalnya untuk menyebut wajan. Konsep wajan yang dikenal oleh masyarakat luas adalah alat dapur yang digunakan untuk menggoreng maupun memasak. Berbeda dengan konsep wajan dalam istilah perbatikan yang dapat dipahami sebagai alat yang digunakan untuk memanaskan malam (ZAHRA BATIK KEBUMEN | blog para pembatik, no date).

Batik di Kebumen tidak hanya berhenti pada batik tulis, tetapi muncul dan berkembang pula batik cap-capan dan batik printing (Nanang, 2018). Oleh karena itu, leksikon perbatikan di Kebumen juga turut berkembang. Berdasarkan artikel yang ditemukan dan dianalisis, ditemukan leksikon perbatikan sebanyak 143. Leksikon tersebut, yaitu 64 leksikon perbatikan berdasarkan alat dan bahan, 31 leksikon perbatikan berdasarkan proses 
Yuli Kristianingsih, Nur Faidah, Yulia Cahyani- Pemertahanan Leksikon dan Makna Kultural Motif Batik Kebumen sebagai Upaya Preservasi Warisan Budaya Bangsa

membatik, 48 leksikon perbatikan berdasarkan motif. Berikut contoh beberapa leksikon perbatikan di Kebumen.

\section{Lekiskon Berdasarkan Alat dan Bahan}

Peralatan membatik adalah alat-alat yang digunakan untuk membatik (Lestari, 2012). Pada dasarnya. peralatan yang digunakan untuk membatik di setiap daerah tidak banyak memiliki perbedaan. Seperti halnya dengan peralatan batik yang berada di Desa Gemeksekti Kabupaten Kebumen. Berikut contoh leksikon berdasarkan alat dan bahan.

Tabel 1. Contoh Leksikon Berdasarkan Alat dan Bahan

\begin{tabular}{lll}
\hline No & Leksikon & \multicolumn{1}{c}{ Makna } \\
\hline 1 & Wangkring & $\begin{array}{l}\text { kayu yang digunakan untuk meletakkan kain saat proses } \\
\text { pembatikan pada batik tulis. } \\
\text { timah, kayu, atau batu yang dimasukkan ke dalam kantong } \\
\text { untuk menahan batik yang telah diberi malam agar tidak } \\
\text { mudah tergeser atau berpindah. } \\
\text { tempat untuk duduk pembatik. }\end{array}$ \\
3 & Dandul & $\begin{array}{l}\text { kayu yang digunakan untuk mengangkat kain pada saat } \\
\text { melorotkan malam. } \\
\text { wadah yang terbuat dari tembaga untuk memanaskan } \\
\text { malam pada proses pembuatan batik cap. }\end{array}$ \\
5 & Loyang & Sumber : (ZAHRA BATIK KEBUMEN I blog para pembatik, no date)
\end{tabular}

Alat dan bahan dalam perbatikan dibedakan berdasarkan jenis batiknya, seperti batik tulis, batik cap, dan batik printing (ZAHRA BATIK KEBUMEN | blog para pembatik, no date). Leksikon dalam batik cap yaitu loyang, angsang, karung meja cap batik, remazol, waterglass, kuas, gelas, dan plastik. Bahan dalam perbatikan yaitu kain mori, mori primissima, kain sutera, kain prima, kain primis, kain katun, kain sanforis, dan malam. Kain mori adalah kain berwarna putih yang biasanya digunakan untuk mengkafani orang yang telah meninggal. Kain ini bertekstur sedikit kasar dan nyaman digunakan.

\section{Leksikon Berdasarkan Proses Membatik}

Proses pembuatan batik adalah tahap-tahap yang harus dilalui untuk membatik (Lestari, 2012). Seperti yang telah kita ketahui pada umumnya jika batik identik dengan menggambarkan pola di atas kain dengan menggunakan 
Yuli Kristianingsih, Nur Faidah, Yulia Cahyani- Pemertahanan Leksikon dan Makna Kultural Motif Batik Kebumen sebagai Upaya Preservasi Warisan Budaya Bangsa

malam. Akan tetapi, terdapat langkah-langkah yang harus dilalui selain hal di atas. Berikut contoh leksikon berdasarkan proses membatik.

Tabel 2. Contoh Leksikon Berdasarkan Proses Membatik

\begin{tabular}{|c|c|c|}
\hline No & Leksikon & Makna \\
\hline 1 & Ngemplong & tahap paling awal atau pendahuluan, diawali dengan mencuci \\
\hline 2 & $\begin{array}{l}\text { Nyorek atau } \\
\text { ngragangi }\end{array}$ & $\begin{array}{l}\text { kain mori untuk menghilangkan kanji. } \\
\text { proses menjiplak atau membuat pola di atas kain mori dengan } \\
\text { cara meniru pola motif yang sudah ada. }\end{array}$ \\
\hline 3 & Nembok/mopok & $\begin{array}{l}\text { proses menutupi bagian-bagian yang tidak boleh terkena } \\
\text { warna dasar menggunakan malam. Memberi 'malam' pada } \\
\text { gambar yang sudah diberi warna agar dalam proses } \\
\text { pewarnaan pada dasar kain, warna gambar pada motif tidak } \\
\text { berubah. }\end{array}$ \\
\hline 4 & $\begin{array}{l}\text { Ngerok dan } \\
\text { Mbirah }\end{array}$ & $\begin{array}{l}\text { mengerok malam pada kain menggunakan lempengan logam, } \\
\text { kemudian kain dibilas dengan air bersih untuk diangin- } \\
\text { anginkan. }\end{array}$ \\
\hline 5 & Ngrining & $\begin{array}{l}\text { proses mengisi bagian yang belum diwarnai dengan motif } \\
\text { tertentu dan dilakukan setelah proses pewarnaan dilakukan. }\end{array}$ \\
\hline
\end{tabular}

Dalam proses membatik di Kebumen, leksikon yang ditemukan yaitu mbathik. Mbathik adalah cara menorehkan malam batik ke kain mori, dimulai dari nglowong dan isen-isen. Nglowong merupakan proses menggambar garisgaris di luar pola, sedangkan isen-isen adalah mengisi pola dengan berbagai macam bentuk. Selain itu, juga terdapat leksikon nyecek dan nruntum. Nyecek merupakan proses membuat isian dalam pola yang sudah dibuat dengan cara memberi titik-titik (nitik), sedangkan nruntum adalah mengisi pola dengan berbagai macam bentuk yang lebih rumit dari isen-isen (ZAHRA BATIK KEBUMEN | blog para pembatik, no date).

\section{Leksikon Berdasarkan Motif Batik}

Motif batik di Kebumen dibedakan berdasarkan pelataran dan isen-isen utamanya. Motif berdasarkan pelataran artinya motif yang isen-isen utamanya merupakan background dari keseluruhan batik itu sendiri. Motif berdasarkan isen-isen artinya motif yang utamanya adalah isen-isen, bukan pelatarann. Motif berdasarkan pelataran adalah salah satu ciri khas dari batik Kebumen (Motif 
Yuli Kristianingsih, Nur Faidah, Yulia Cahyani- Pemertahanan Leksikon dan Makna Kultural Motif Batik Kebumen sebagai Upaya Preservasi Warisan Budaya Bangsa

Batik Kebumen, 2019). Meskipun demikian, juga ditemukan motif batik yang tidak berdasarkan pelarannya, akan tetapi berdasarkan isen-isennya. Berikut contoh leksikon berdasarkan motif batik di Kebumen.

Tabel 3. Contoh Leksikon Berdasarkan Motif Batik

\begin{tabular}{|c|c|c|}
\hline No & Leksikon & Makna \\
\hline 1 & Gringsing & $\begin{array}{l}\text { Motif batik yang berbentuk bulatan kecil yang tersusun rapi, } \\
\text { bagian tengahnya berlubang, berukuran kecil, bagian } \\
\text { pinggirnya berwarna putih dilengkapi ornamen burung, Bunga } \\
\text { dan tanaman yang ditemukan di kebumen. }\end{array}$ \\
\hline 2 & Lawet & motif yang menggambarkan burung lawet \\
\hline 3 & Pring sedapur & $\begin{array}{l}\text { menggambarkan pohon bambu/pring beserta kehidupan alam } \\
\text { disekitarnya seperti aneka burung yang menghinggapi pohon } \\
\text { bambu tersebut }\end{array}$ \\
\hline 4 & senen romo & $\begin{array}{l}\text { penggambaran dari "kehidupan yang semi" (kehidupan yang } \\
\text { berkembang atau makmur) yang berhubungan dengan } \\
\text { kehidupan daratan, udara dan laut/air }\end{array}$ \\
\hline 5 & Limaran & $\begin{array}{l}\text { merupakan pelataran yang berbentuk belah ketupat yang } \\
\text { berjajar }\end{array}$ \\
\hline
\end{tabular}
Batik ... - Google Buku, 2015; Firmansah, 2015)

Contoh (1) merupakan salah satu motif batik berdasarkan pelatarannya. Motif batik lain yang juga didasarkan pada pelatarannya yaitu motif ukel. Disebut motif ukel karena merupakan pelataran yang berbentuk garis ukel Motif ukel terdiri dari ukel cantel, ukel tombel, ukel rambat, dan ukel muthu.(Majalah Adiluhung Pelestari Budaya Nusantara Edisi 07: Wayang, Keris, Batik ... - Google Buku, 2015). Selain itu, contoh (2) merupakan salah satu motif batik berdasarkan isen-isen dominannya. Contoh lain dari motif ini yaitu sekar jagat/jagatan. Sekar artinya bunga, jagat artinya dunia. Jadi, sekar jagat adalah dunia bunga atau apapun yang mencakup semua unsur alam (Kartyadi, 2019). Motif jagatan terdiri dari jagatan sawah, jagatan puntal, jagatan lawet, jagatan rantai, dan jagatan buntal (Motif Batik Kebumen, 2019).

\section{b. Makna Kutural}

Berdasarkan analisis dari artikel yang relevan, dapat diketahui bahwa batik Kebumen lebih berkembang murni sebagai seni batik yang menekankan 
pada nilai artistik bukan pada nilai makna di balik sebuah gambar. Batik Kebumen lebih berorientasi pada alam (ekologis) yang menggambarkan masyarakat Kebumen yang bersahaja dan sangat menghormati kehidupan yang ditawarkan oleh alam (Wibiono, 2012).

Menurut Ketua Paguyuban Batik Lawet Sakti Kebumen, H. Hamami Abdul Rohman, motif batik Kebumen yang dibuat terinspirasi dari budaya Kebumen, sehingga muncul kekhasan warna dan coraknya. Secara umum, ide dasar pembuatan motif batik berasal dari apa saja. Bisa dari alam sekitar, seperti bunga yang tumbuh di halaman, daun, atau corak batik yang bagus kemudian dikembangkan (Wibiono, 2012). Motif batik tersebut seperti tutul byur, kembang jeruk, dan jahe tutul. Meskipun demikian, juga ditemukan motif batik yang memiliki makna kultural. Berikut contoh motif batik yang memiliki makna kultural.

Tabel 4. Contoh Motif Batik Yang Memiliki Makna Kultural

\begin{tabular}{|c|c|c|}
\hline No & Nama motif & Makna kultural \\
\hline 1 & $\begin{array}{l}\text { Batik } \\
\text { gringsing }\end{array}$ & $\begin{array}{l}\text { Secara filosifis, batik gringsing menggambarkan tentang } \\
\text { keseimbangan, kesuburan dan kemakmuran. Karena termasuk } \\
\text { batik tertua, warna yang digunakannya pun juga masih } \\
\text { menggunakan warna-warna alami yang diambil dari warna } \\
\text { dari tumbuh-tumbuhan. }\end{array}$ \\
\hline 2 & Batik ukel & $\begin{array}{l}\text { Batik ukel memiliki filosoli kewibawaan yang besar. Konon, } \\
\text { dahulu batik ukel juga sering dikenakan oleh keluarga } \\
\text { kerajaan yang memang diidentikan memliiki kewibawaan } \\
\text { yang kuat. }\end{array}$ \\
\hline
\end{tabular}

Sumber: (Majalah Adiluhung Pelestari Budaya Nusantara Edisi 07: Wayang, Keris, Batik ... - Google Buku, 2015; Purnamasari, 2016)

\section{c. Preservasi Budaya Perbatikan Kebumen Melalui Leksikon dan Makna Kultural}

Menurut Kamus Besar Bahasa Indonesia (KBBI), preservasi adalah pengawetan, pemeliharaan, penjagaan dan perlindungan (sumber daya alam, budaya, dsb) agar terjamin kehidupannya sepanjang masa. Berdasarkan pengertian tersebut, preservasi batik Kebumen yaitu usaha untuk melestarikan budaya perbatikan agar tetap terjaga keutuhan dan kelestarian motif batiknya, sehingga dapat diwariskan kepada generasi yang akan datang. Preservasi 
Yuli Kristianingsih, Nur Faidah, Yulia Cahyani- Pemertahanan Leksikon dan Makna Kultural Motif Batik Kebumen sebagai Upaya Preservasi Warisan Budaya Bangsa

budaya batik di Kebumen penting untuk dilakukan. Hal ini karena perbatikan di Kebumen kurang dikenal dan hanya diketahui oleh masyarakat daerah perbatikan saja.

Preservasi perbatikan Kebumen dapat dilakukan dari leksikon, motif batik, dan makna kulturalnya. Berdasarkan hasil temuan leksikon, dapat dilakukan upaya preservasi dengan pembuatan kamus batik Kebumen, baik berbentuk cetak maupun digital. Selain itu, leksikon yang ditemukan dapat digunakan untuk mengetahui perbedaan antara leksikon batik di Kebumen dengan daerah penghasil batik lainnya. Berdasarkan hasil temuan motif dan makna kulturalnya dapat dibuat buku yang berisi motif batik, penjelasan motif, gambar, maupun sejarahnya. Sehingga masyarakat dapat mengetahui batik di Kebumen tidak hanya dari budaya lisan saja.

Pengenalan motif batik kepada masyarakat dapat dilakukan dengan pemasangan reklame di sepanjang jalan ataupun penggunaan videotron. Di samping itu, cara lain yang dapat ditempuh yaitu dengan memanfaatkan motif batik kebumen sebagai seragam sekolah maupun kantor serta motif batik dapat juga dibuat souvenir khas kebumen yang dipasarkan di objek wisata Kebumen. Sehingga motif batik Kebumen akan lebih dikenal oleh masayarakat, baik masyarakat setempat maupun luar Kebumen. Hal ini juga akan mendorong industri perbatikan di Kebumen. Dengan demikian, perbatikan di Kebumen juga turut terjaga kelestariannya.

\section{SIMPULAN}

Berdasarkan uraian di atas, dapat disimpulkan bahwa terdapat 143 leksikon perbatikan di Kebumen yang diperoleh dari identifikasi dan analisis berbagai referensi di internet. Leksikon berdasarkan alat dan bahan sebanyak 64 leksikon. Leksikon berdasarkan proses pembuatan sebanyak 31 leksikon. Leksikon berdasarkan motif batik di Kebumen sebanyak 48 leksikon. Selain itu, tidak semua motif batik memiliki makna kultural, tetapi hanya memiliki nilai 
artistik saja. Motif batik yang memiliki makna kultural adalah gringsing, ukel, limaran, dan skrikit.

Dari hasil identifikasi dan analisis leksikon perbatikan dan makna kultural motif batik di Kebumen diharapkan dapat dijadikan sebagai langkah awal preservasi budaya batik di Kebumen. Leksikon dan motif-motif batik Kebumen yang ditemukan dapat dijadikan sumber acuan pengenalan batik Kebumen. Dengan demikian, batik Kebumen diharapkan akan tetap lestari.

\section{DAFTAR PUSTAKA}

Arti kata - Kamus Besar Bahasa Indonesia (KBBI) Online (no date). Available at: https://kbbi.web.id/ (Accessed: 22 September 2020).

Fatehah, N. (2010). Kajian etnolinguistik. Jurnal Bahasa dan Sastra UIN Sunan Kalijaga Yogyakarta, 9(2).

Firmansah (2015) Batik Lawet: budaya Indonesia. Available at: https:/ / budayaindonesia.org/ Batik-Lawet (Accessed: 7 September 2020).

Fitinline. (2013). Batik Kebumen. Available at: https:/ / fitinline.com/article/read/batik-kebumen/ (Accessed: 7 September 2020).

Gani, S. and Arsyad, B. (2019). Kajian teoritis struktur internal bahasa (fonologi, morfologi, sintaksis, dan semantik). A Jamiy : Jurnal Bahasa dan Sastra Arab, 7(1), p. 1. doi: 10.31314/ajamiy.7.1.1-20.2018.

Gareta, S. P. (2019). Pendapatan ekspor industri batik capai 18 juta dolar AS ANTARA News Bali. Bali Antara. https:/ / bali.antaranews.com/berita/163088/pendapatan-eksporindustri-batik-capai-18-juta-dolar-as (Accessed: 24 September 2020).

Kartyadi, T. (2019). Tanuraksan Kampung Batik di Kebumen: Bernasnews. https:/ / bernasnews.com/tanuraksan-kampung-batik-di-kebumen/ (Accessed: 7 September 2020).

Khoerunnisa, R. (2012). Upaya pengembangan sentra industri batik di Desa Gemeksekti Kecamatan Kebumen Kabupaten Kebumen. (Unpublished Thesis). Universitas Negeri Yogyakarta: Yogyakarta.

Kridalaksana, H. (1994) Kelas kata dalam bahasa Indonesia. Ketiga. Jakarta: Gramedia Pustaka.

Kridalaksana, H. (2008) Kamus linguistik. Jakarta: Gramedia Pustaka Utama.

Lestari, S. D. (2012) Mengenal aneka batik. Jakarta: Balai Pustaka. 
Yuli Kristianingsih, Nur Faidah, Yulia Cahyani- Pemertahanan Leksikon dan Makna Kultural Motif Batik Kebumen sebagai Upaya Preservasi Warisan Budaya Bangsa

Majalah Adiluhung Pelestari Budaya Nusantara Edisi 07: Wayang, Keris, Batik ... Google Buku (2015). Available at:

https:/ / books.google.co.id/books?id=2BulDwAAQBAJ\&pg=PA34\&lpg $=$ PA34\&dq=batik+kebumen\&source $=$ bl\&ots $=$ HdX2Jmsafz\&sig=ACfU3U 1zF2P19V8PEJZnIr0TGdsgaS64Fg\&hl=id\&sa=X\&ved=2ahUKEwjGvauz8_rAhVv6nMBHZyhDkw4RhDoATAFegQIBRAB\#v=onepage\&q=batik kebumen\&f=false (Accessed: 7 September 2020).

Tanpa Nama. (2019). Motif batik Kebumen. Motif Batik. https:/ / www.motifbatik.web.id/2019/05/motif-batikkebumen.html?m=1 (Accessed: 7 September 2020).

Muhammad. (2011). Metode penelitian bahasa. Yogyakarta: Ar-ruzz Media.

Nanang, W. (2018) Industri batik Kebumen alami pasang surut. Koran Bernas. https:/ / arsip.koranbernas.id/industri-batik-kebumen-alami-pasangsurut/ (Accessed: 7 September 2020).

Nurhidayat, S. (2010). Eksistensi dan Perlindungan karya cipta motif batik Kebumen sebagai kekayaan intelektual tradisional. (Unpublished Thesis). Universitas Diponegoro: Semarang.

Prasetyo, A. (2010). Karya agung warisan budaya dunia. Yogyakarta:Pura Pustaka.

Purnamasari, D. A. (2016). Sejarah perkembangan makna dan nilai filosofis batik srikit khas Kabupaten Kebumen Provinsi Jawa Tengah. ADITYAPendidikan Bahasa dan Sastra Jawa, 8(1), 7-17.

Purwaningsih, D. R., Sholikhah, I. M. and Wardani, E. (2018). Redefining Banyumas local values: symbolisms in batik motifs. Lingua Cultura, 12(3), p. 295. doi: 10.21512/lc.v12i3.4206.

Spradley, J. P. (2007) Metode etnografi. II. Yogyakarta: Tiara Wacana.

Subroto, E. (2011) Pengantar studi semantik dan pragmatik. Surakarta: Cakrawala Media. Available at:

http:/ / katalogdisarpussukoharjo.perpusnas.go.id/detail-opac?id=18320.

Wibiono, B. (2012) Dunia Sosial budaya: motif-motif batik Kebumen: makna dan upaya pelestariannya. Available at:

http:/ / duniasosbud.blogspot.com/2012/09/motif-motif-batikkebumen-makna-dan.html (Accessed: 7 September 2020).

ZAHRA BATIK KEBUMEN. (No Date). Blog para pembatik. Available at: https:/ / zahrabatikkebumen.wordpress.com/ (Accessed: 7 September 2020). 